\title{
Photo-inhibition of pitting corrosion on types 304 and 316 stainless steels in chloride-containing solutions
}

\author{
Carmel B. Breslin,* Digby D. Macdonald, Elzbieta Sikora† and Janusz Sikora
}

Center for Advanced Materials, The Pennsylvania State University, 517 Deike Building, University Park, PA 16802, U.S.A.

(Received 1 August 1995)

\begin{abstract}
The influence of incident monochromatic $u v$ light on the susceptibility of types 304 and 316 stainless steels to pitting corrosion in chloride-containing solutions is described. Illumination of the immersed surfaces, in neutral and acidic solutions, gave rise to an enhanced resistance to the onset of pitting corrosion that persisted for some $220 \mathrm{~h}$ after the irradiation had been removed. This was evident from an increase in the breakdown potential, longer induction periods, and notable changes in the current noise at constant potentials for specimens polarized under illumination. It was found that the degree of inhibition to pitting attack depended on the photon energy, the illumination period and the nature of the passive film. Higher breakdown potentials and longer induction periods were observed with high energy photons $(\lambda<375 \mathrm{~nm})$; these photons having energies in excess of the bandgap energy. Also, the photo-inhibition effect increased with the period of illumination; the maximum effect being observed following a 5-h illumination period. A much reduced photo-inhibition effect was observed for specimens polarized in alkaline solutions. This was attributed to the formation of a precipitate layer at the film-solution interface, which hindered the interaction of the incident photons with the barrier layer. Copyright (C) 1996 Elsevier Science Ltd
\end{abstract}

Key words: pitting, photo-inhibition, stainless steels, chloride, $u v$ light.

\section{INTRODUCTION}

The breakdown of passive films that form on metals and alloys, and the initiation and propagation of localized corrosion, are major concerns in corrosion engineering and are of great fundamental interest in electrochemistry. Various attempts, ranging from the addition of alloying elements to the base material [1-4] to the addition of inhibitor-containing solutions to the environment [5], have been made in an effort to enhance the passivity of metals and alloys.

Recently, it has been shown that inhibition of localized corrosion can be achieved by illuminating immersed electrodes with $u v /$ visible photons. The first observation of this kind was reported for polycrystalline nickel in chloride-containing solutions on illuminating with incident white light [6]. More recently, an anodic shift in the breakdown potential

*Permanent address: Department of Chemistry, St Patrick's College, Maynooth, Ireland.

tOn leave from the Institute of Physical Chemistry, Polish Academy of Sciences, Warsaw, Poland. of type 304SS in chloride solutions was found in the presence of $u v$ light [7], while stronger photoinhibition effects were observed for pure iron $[8,9]$ under high intensity $u v$ irradiation. Although it was reported, in some earlier studies, that the rate of corrosion of mild steel in citrate- and sulphatecontaining solutions increased on illuminating with white light $[10,11]$, these more recent studies suggest that illumination with high energy photons leads to a modification of the passive film that results in an increased resistance to the onset of pitting attack.

In this communication the photo-inhibition of pitting on types 316 and 304 stainless steels in chloride-containing solutions, and the factors affecting the degree of photo-inhibition, are reported. These findings are explained within the framework of the point defect model (PDM) [12] for the growth and breakdown of passive films.

\section{EXPERIMENTAL}

Test specimens were prepared from $304(0.08 \% \mathrm{C}$, $2.0 \% \mathrm{Mn}, 18.0 \% \mathrm{Cr}, 8.0 \% \mathrm{Ni}, 0.04 \% \mathrm{P}, 0.003 \% \mathrm{~S}$, 
$1.0 \% \mathrm{Si})$ and $316(0.08 \% \mathrm{C}, 2.0 \% \mathrm{Mn}, 16.0 \% \mathrm{Cr}$, $12.0 \% \mathrm{Ni}, 0.04 \% \mathrm{P}, 0.003 \% \mathrm{~S}, 1.0 \% \mathrm{Si}, 2.0 \% \mathrm{Mo}$ ) stainless steel rods, which were covered with lacquer, mounted in a PVC holder, and embedded in a two-component epoxy resin. The exposed surface, approximately $0.8 \mathrm{~cm}^{2}$ in area, was polished mechanically with successively finer grades of $\mathrm{SiC}$ paper and $0.05 \mu \mathrm{m}$ alumina powder to a mirror finish.

The electrochemical cell consisted of a threeelectrode PTFE cell equipped with a quartz window to allow irradiation of the test electrodes. A saturated calomel electrode (sce) was used as the reference electrode and a platinum wire, coiled inside the cell, was used as the auxiliary electrode. All test solutions were prepared from Analar-grade reagents and deionized water and were deoxygenated with nitrogen. The $\mathrm{pH}$ of the solutions was adjusted to 7.5 with $\mathrm{NaOH}$ or, alternatively, was buffered to $\mathrm{pH} 7.5$ with a $0.15 \mathrm{~mol} \quad \mathrm{dm}^{-3} \quad \mathrm{H}_{3} \mathrm{BO}_{3} / 0.007 \mathrm{~mol} \mathrm{dm}^{-3}$ $\mathrm{Na}_{2} \mathrm{~B}_{4} \mathrm{O}_{7}$ solution.

The working electrodes were irradiated at wavelengths between 300 and $425 \mathrm{~nm}$ using a $150 \mathrm{~W}$ $u v$-enhanced Xe lamp (Oriel Model 6254) and a 1/8 monochromator (Oriel Model 77250). The incident power density at $300 \mathrm{~nm}$ was $0.04 \mathrm{~mW} \mathrm{~cm} \mathrm{c}^{-2}$, giving a photon flux of $6.04 \times 10^{14} \mathrm{~cm}^{-2}$. The photon flux was maintained at approximately this value at each wavelength by adjusting the light intensity at the surface.

Electrochemical tests were carried out using a Solartron/Schlumberger Electrochemical Interface (Model 1286). In potentiodynamic polarization tests, the working electrodes were polarized at a rate of $0.1 \mathrm{mV} \mathrm{s}^{-1}$ in the anodic direction up to the breakdown potential. In illumination experiments, the electrodes were illuminated continuously throughout the potential scan. The breakdown potential was recorded as the potential at which the current exceeded $80 \mu \mathrm{A} \mathrm{cm} \mathrm{cm}^{-2}$. In current-time measurements the electrodes were initially polarized at a potential in the passive region for a $30-\mathrm{min}$ period, and then the potential was stepped to an appropriate point where meta-stable pitting could be observed for the non-illuminated specimens, and the current transients were recorded as a function of time, using a Keithley Model 576 data acquisition unit at a sampling rate of $90 \mathrm{mS}$. For the illumination

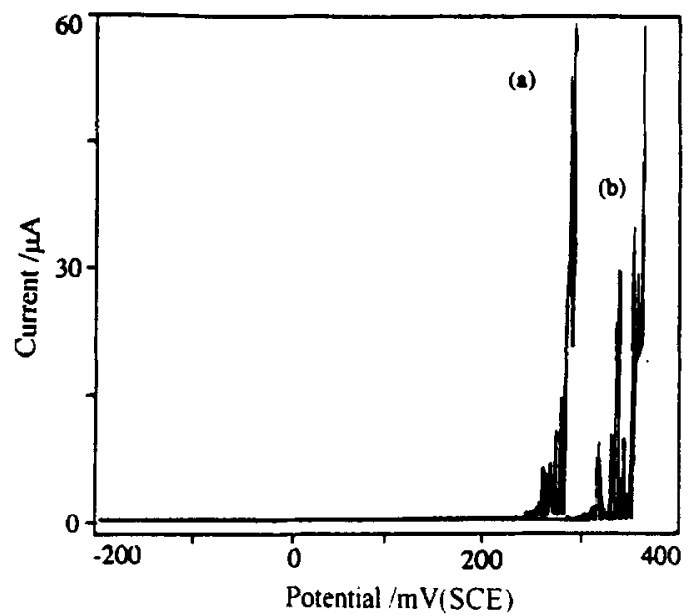

Fig. 1. Potentiodynamic polarization curves for type 304 stainless steel in a neutral $0.5 \mathrm{~mol} \mathrm{dm}{ }^{-3} \mathrm{NaCl}$ solution under conditions of (a) non-illumination and (b) illumination at $300 \mathrm{~nm}$.

experiments, the electrodes were illuminated continuously throughout the entire experiment. Additional experiments involving polarizing the working electrodes, under illumination for periods of up to 15 hours, and then determining the breakdown potential using the potentiodynamic polarization method. Exactly the same polarization periods were used for the illuminated and non-illuminated electrodes.

\section{RESULTS}

Typical anodic polarization curves recorded for type 304 stainless steel in a neutral $0.5 \mathrm{~mol} \mathrm{dm}^{-3}$ $\mathrm{NaCl}$ solution (unbuffered) under conditions of illumination $(300 \mathrm{~nm})$ and non-illumination are shown in Fig. 1. It is evident that an increase in the pitting resistance occurs on illumination of the electrode; both the breakdown potential and the potential which coincides with the appearance of the first meta-stable pitting events are shifted in the noble direction. The effect of illumination on the breakdown potentials can be seen more clearly from the data presented in Table 1, where the breakdown potentials of 304 and 316 stainless steels, averaged over at least three separate determinations (shown in parentheses is the actual number of tests carried out),

Table 1

Breakdown potential data for types 304 and 316 stainless steels under conditions of illumination $(300 \mathrm{~nm})$ and non-illumination. Numbers in parentheses indicate the number of experiments over which the data were averaged

\begin{tabular}{llclcc}
\hline & \multicolumn{3}{c}{ Breakdown potential (mV (sce)) } \\
& \multicolumn{2}{c}{304} & & \multicolumn{2}{c}{316} \\
\cline { 2 - 3 } \cline { 5 - 6 }$\left(\mathrm{Cl}^{-}\right]$ & \multicolumn{1}{c}{ Dark } & Light & & Dark & Light \\
\hline $2.5 \times 10^{-2}$ & $355 \pm 7(3)$ & $420 \pm 10(3)$ & $430 \pm 10(3)$ & $490 \pm 11(4)$ \\
0.50 & $275 \pm 18(30)$ & $350 \pm 20(22)$ & $330 \pm 20(17)$ & $395 \pm 20(17)$ \\
2.0 & $160 \pm 8(4)$ & $210 \pm 15(5)$ & $230 \pm 12(5)$ & $290 \pm 10(4)$ \\
\hline
\end{tabular}




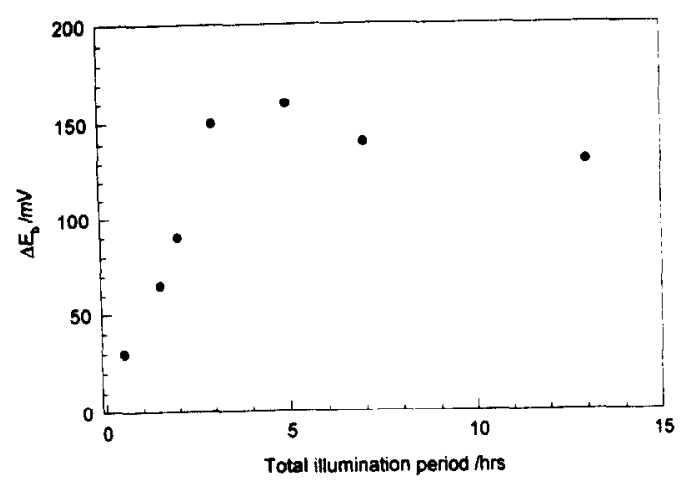

Fig. 2. Displacement in the breakdown potential, $\Delta E_{\mathrm{b}}$, as a function of the illumination period for $\mathrm{SS} 316$ polarized at $+250 \mathrm{mV}($ sce $)$ in a buffered $0.1 \mathrm{~mol} \mathrm{dm}^{-3} \mathrm{NaCl}$ solution prior to measuring the breakdown potential in a buffered

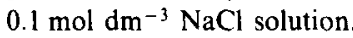

are shown as a function of the chloride concentration. In each case, an increase of about $60 \mathrm{mV}$ in the breakdown potential can be observed on irradiation, with the maximum degree of uncertainty being of the order of $\pm 40 \mathrm{mV}$. A further significant factor is that the breakdown potentials of the illuminated SS304 specimens approach those of the SS316 specimens, as measured in the dark, indicating perhaps a comparable degree of passivity enhancement between alloying and illumination under these conditions.

An even greater increase in the breakdown potential, of the order of $150 \pm 50 \mathrm{mV}$, was observed on prior illumination of the specimens at $300 \mathrm{~nm}$ for periods exceeding $5 \mathrm{~h}$. In these experiments, the electrodes were polarized in a $0.1 \mathrm{~mol} \mathrm{dm}^{-3} \mathrm{NaCl}$ solution (buffered) at $+250 \mathrm{mV}$ (sce) for various periods of time under conditions of illumination and non-illumination. The specimens were then polarized from $+250 \mathrm{mV}(\mathrm{sce})$ in the anodic direction at a rate of $0.1 \mathrm{mV} \mathrm{s}^{-1}$ up to the breakdown potential. The displacement in the breakdown potential was calculated by subtracting the average breakdown potential for the specimens polarized in the dark from the average breakdown potential for the specimens polarized in the light. Each experiment was repeated three times. These data are presented in graphical form in Fig. 2, where the average displacement in the breakdown potential, $\Delta E_{\mathrm{b}}$, is shown as a function of the prior illumination period.

Further evidence for photo-inhibition of pitting attack was obtained from current-time measurements, where current-decay transients were monitored as a function of time for illuminated $(300 \mathrm{~nm})$ and non-illuminated specimens. Representative plots are shown in Fig. 3(a) and (b) for SS316 under conditions of non-illumination and illumination, respectively. The specimens were passivated initially at $250 \mathrm{mV}$ (sce) in a $0.1 \mathrm{~mol} \mathrm{dm}^{-3} \mathrm{NaCl}$ solution (buffered) for a 30-min period. Then the potential was stepped to $420 \mathrm{mV}$ (sce) and the current recorded. Exactly the same procedure was followed for both the illuminated and non-illuminated electrodes. A significant degree of meta-stable pitting, reflected by the frequent fluctuations in the current in Fig. 3(a), was observed for the non-illuminated electrode. However, this current noise was removed almost completely on illumination, indicating the absence of meta-stable pitting attack. This higher degree of passivity appeared to survive; even after a 12-h polarization period no current fluctuations were observed. Although the sustained passivation in this case may also be connected with prolonged polarization, a similar degree of enhanced passivation was observed on illuminating the specimens only for the initial $30-\mathrm{min}$ period. Subsequent polarization at $420 \mathrm{mV}$ (sce) (in the dark) resulted in current-decay profiles similar to that shown in Fig. 3(b), thus indicating that continued illumination is not a prerequisite in achieving this enhanced resistance to pitting attack. Similar behaviour was observed for type 304 stainless steel on illumination.

In order to quantify the "permanent nature" of the photo-inhibition effect, the pitting susceptibility of SS316 was studied at various periods of time following illumination. The specimens were illuminated at $300 \mathrm{~nm}$ for $80 \mathrm{~min}$ under polarizing conditions in a neutral $0.5 \mathrm{~mol} \mathrm{dm}{ }^{-3} \mathrm{NaCl}$ solution. The specimens were then immersed under opencircuit conditions (dark) in a borate buffer solution ( $\mathrm{pH}$ of 7.5) removed at selected intervals, and the breakdown potential determined in a neutral $0.5 \mathrm{~mol}$ $\mathrm{dm}^{-3} \mathrm{NaCl}$ solution using the potential scan method. Identical experiments were carried out in the dark (ie. without the illumination period); the specimens were polarized in the chloride solution (dark) for $80 \mathrm{~min}$, removed and immersed in the borate solution, and the breakdown potential determined at selected intervals. Data collected in this manner for periods up to $350 \mathrm{~h}$ are presented in Fig. 4, where the breakdown potential for the illuminated and non-illuminated specimens is shown as a function of the immersion period following illumination or polarization. In Fig. 4(a), the data are displayed on a linear plot, while in Fig. 4(b), the data are displayed on a semi-logarithmic plot allowing a clearer presentation of the data collected for short immersion periods. A clear difference between the breakdown potentials measured for the illuminated and non-illuminated specimens can be seen for immersion periods up to approximately $220 \mathrm{~h}$, indicating that the photoinhibition effect persists over this period of time. The gradual ennoblement in the breakdown potentials with immersion period may be attributed to a chromium-enrichment in the passive film or a crystallization process. This process occurred also with the illuminated specimens. As before, a similar trend was observed for SS304.

The influence of solution $\mathrm{pH}$ on the extent of photo-inhibition was studied by polarizing and illuminating the electrodes in solutions of varying acidity. A $0.5 \mathrm{~mol} \mathrm{dm}^{-3} \mathrm{NaCl}$ solution was used as 
the test solution, but the $\mathrm{pH}$ was adjusted to the desired value by the addition of $\mathrm{NaOH}$ or $\mathrm{HCl}$. All irradiation experiments were carried out at $300 \mathrm{~nm}$. The breakdown potentials were determined from polarization measurements for specimens polarized in the dark and under conditions of continuous illumination. Each experiment was carried out at least three times. The displacement in the breakdown potential, $\Delta E_{\mathrm{b}}$, was calculated as $\Delta E_{\mathrm{b}}=E_{\mathrm{b}}$ (light) -
$E_{\mathrm{b}}$ (dark). The average displacements in the breakdown potential for SS304 and SS316 are shown as a function of the solution $\mathrm{pH}$ in Figs $5(\mathrm{a})$ and (b), respectively; the degree of scatter in the average displacements being $\pm 30 \mathrm{mV}$. An essentially constant increase in the breakdown potentials, approximately $60 \mathrm{mV}$, was observed on illumination, except for those specimens polarized in the alkaline solutions, where no apparent photo-inhibition effect
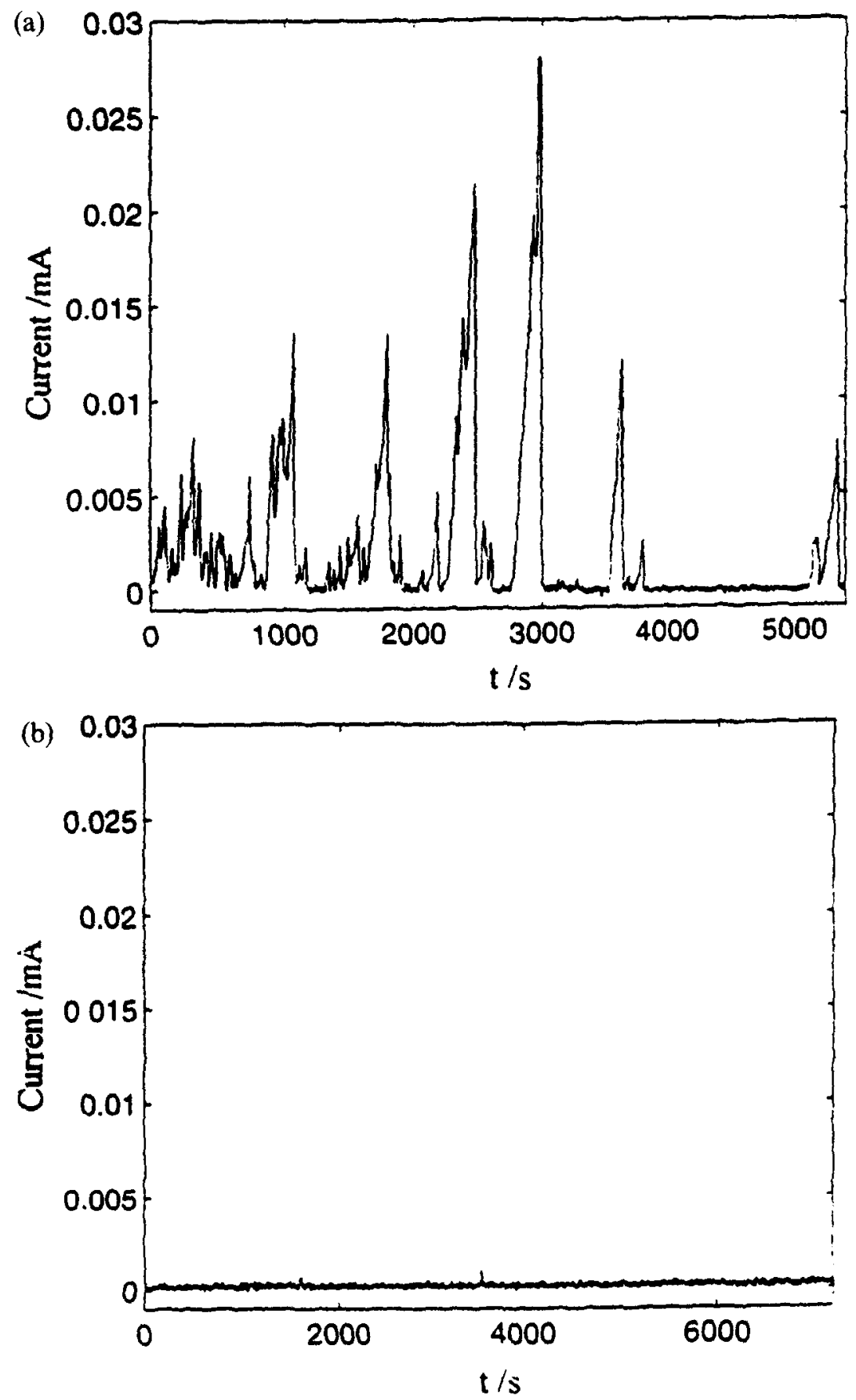

Fig. 3. Current time decay profiles for type 316 stainless steel polarized in a buffered 0.1 mol dm-3 $\mathrm{NaCl}$ solution at $420 \mathrm{mV}$ (sce) following an initial $30-\mathrm{min}$ polarization period at $250 \mathrm{mV}$ (sce) in the same solution: (a) non-illumination, (b) illumination at $300 \mathrm{~nm}$. 


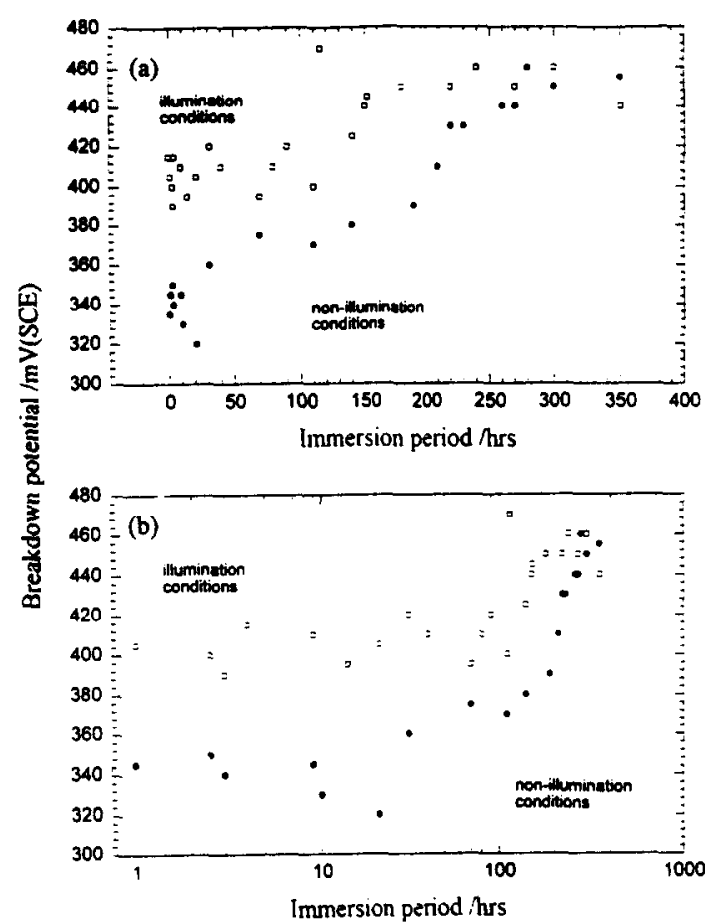

Fig. 4. Breakdown potential of illuminated and non-illuminated SS316 in $0.5 \mathrm{~mol} \mathrm{dm}^{-3} \mathrm{NaCl}$ solution as a function of the immersion period in a borate buffer solution (dark) following polarization or polarization and illumination at $300 \mathrm{~nm}$. (a) Data displayed on a linear plot, (b) data displayed on a semi-logarithmic plot.

was detected. However, it was found that the photo-inhibition effect was partially restored, under these alkaline conditions ( $\mathrm{pH}$ of 10 ), by the addition of a $0.01 \mathrm{~mol} \mathrm{dm}{ }^{-3}$ EDTA solution to the test
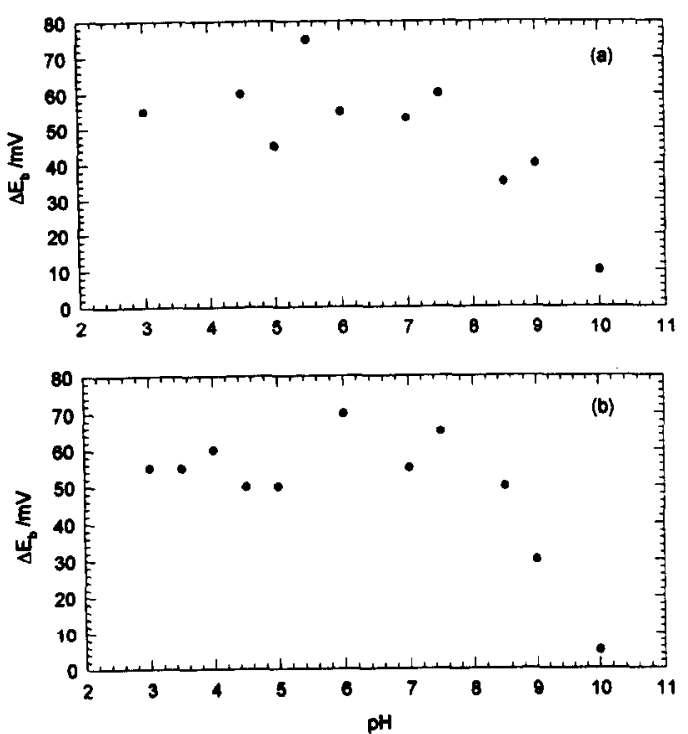

Fig. 5. Displacement in the breakdown potential, $\Delta E_{\mathrm{b}}$, as a function of the $\mathrm{pH}$ of a $0.5 \mathrm{~mol} \mathrm{dm} \mathrm{dm}^{-3} \mathrm{NaCl}$ solution: (a) on illumination of SS304 at $300 \mathrm{~nm}$, (b) on illumination of SS316 at $300 \mathrm{~nm}$.
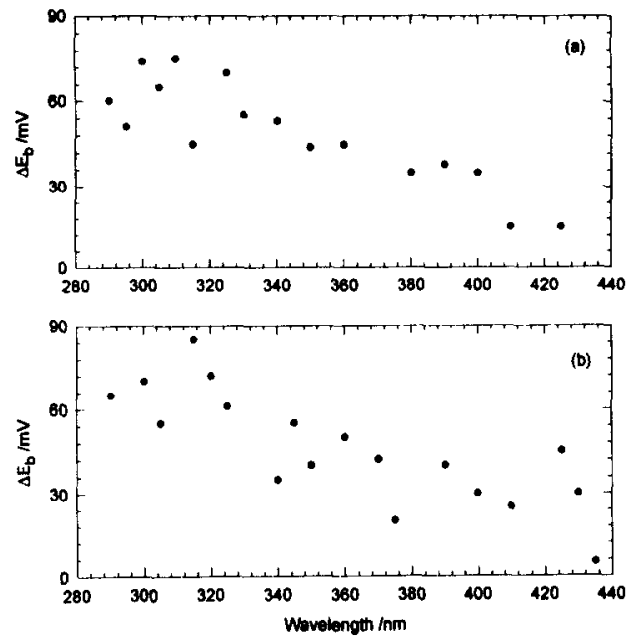

Fig. 6. Displacement in the breakdown potential, $\Delta E_{\mathrm{b}}$, measured in a $0.5 \mathrm{~mol} \mathrm{dm}{ }^{-3} \mathrm{NaCl}$ solution, as a function of the wavelength of the incident light: (a) on illumination of SS304, (b) on illumination of SS316.

solution (the $\mathrm{pH}$ was adjusted with $\mathrm{NaOH}$ and maintained at 10 on addition of the complexing agent). The average displacements in the breakdown potentials for both SS304 and SS316 at a pH of 10.0 on addition of the EDTA solution were 45 and $50 \mathrm{mV}$, respectively. The presence of EDTA at other $\mathrm{pH}$ values did not enhance the photo-inhibition effect. This seems to suggest that the precipitated (outer) layer formed on the barrier layer of the passive film in alkaline environments is photo-electrochemically inactive, but that the addition of a chelating agent hinders the formation of this layer, allowing the photons to reach the barricr layer.

In Figs 6(a) and (b), the effects of variations in the photon energy on the degree of photo-inhibition, as reflected in the displacement in the breakdown potential, are shown for SS304 and SS316, respectively. A constant photon flux was maintained at each wavelength. A neutral $0.5 \mathrm{~mol} \mathrm{dm}{ }^{-3} \mathrm{NaCl}$ solution was used as the test solution. A total of twenty experiments were carried out for each of the stainless steels under conditions of non-illumination in order to obtain adequate "reference" breakdown potentials. The amount of scatter in the breakdown potentials, under these conditions, was of the order of $\pm 20 \mathrm{mV}$. The mean value of the breakdown potential calculated for the 304 stainless steel specimens in the dark was $272 \mathrm{mV}$ (sce), while that for the 316 stainless steel, also polarized in the dark, was $330 \mathrm{mV}$ (sce). Displacements in the breakdown potential, $\Delta E_{\mathrm{b}}$, on illumination were calculated as:

$$
\Delta E_{\mathrm{b}}=\left(E_{\mathrm{b} \text { (light) }}-275\right) \mathrm{mV} \text { for SS304, }
$$

and

$$
\Delta E_{\mathrm{b}}=\left(E_{\mathrm{b}(\mathrm{light})}-330\right) \mathrm{mV} \text { for SS316. }
$$

It can be seen from Fig. 6 that the degree of photo-inhibition depends on the energy of the 


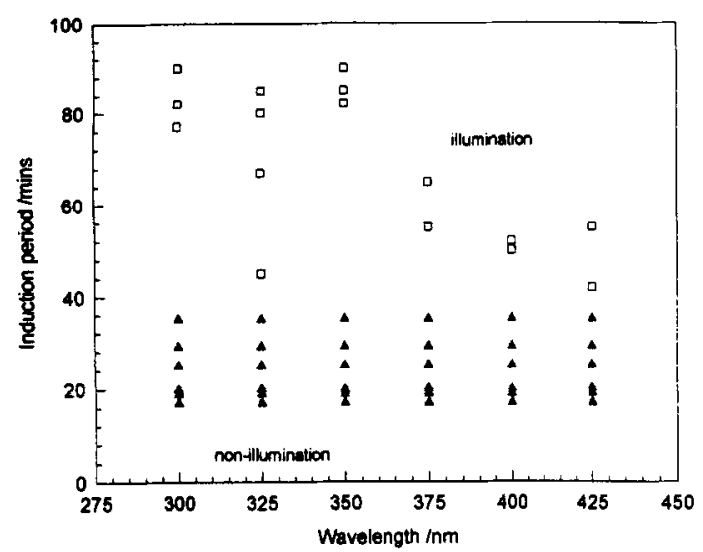

Fig. 7. Measured induction periods as a function of the wavelength of the incident light for SS316 polarized at $+285 \mathrm{mV}$ (sce) in $0.025 \mathrm{~mol} \mathrm{dm}^{-3} \mathrm{NaCl}$ solution. Induction periods measured under conditions of non-illumination are included also, marked by dark symbols, and are plotted at each wavelength for comparative purposes.

photons, with the photo-inhibition effect decreasing with wavelengths exceeding $375 \mathrm{~nm}$.

In Fig. 7, the induction periods for SS316 specimens polarized at $+285 \mathrm{mV}($ sce $)$ in a $0.025 \mathrm{~mol}$ $\mathrm{dm}^{-3} \mathrm{NaCl}$ solution are shown as a function of photon energy. Also shown on this plot are the induction periods measured for identical experiments carried out in the dark. These data points are plotted at each wavelength so that the increase in the induction period on illumination is evident. The induction periods were measured as the time elapsed between the application of the polarizing potential, and the first meta-stable pitting events in which the current exceeded $500 \mathrm{nA}$. Representative plots, in which the current-time transients for SS316 polarized in the dark and polarized and illuminated at $300 \mathrm{~nm}$ are compared, are shown in Fig. 8. Pit initiation, marked by the onset of current oscillations, was observed for the non-illuminated specimen after the elapse of approximately $25 \mathrm{~min}$, while on illumination, the induction period was increased by a factor of three. Again, it is evident from Fig. 7 that the induction period is a function of the photon energy, falling slightly with lower energies.

\section{DISCUSSION}

In previous papers $[6,7]$ we have explained the photo-inhibition of pitting within the framework of the point defect model (PDM) [12] for the growth and breakdown of passive films in terms of the photo-quenching of the electric field $(c)$ within the barrier layer. According to the PDM, passivity breakdown occurs when a critical concentration of cation vacancies coalesces at the metal-film interface to induce mechanical instability and rupture of the passive film. These ideas may be assembled to derive expressions for the critical breakdown potential $\left(V_{\mathrm{c}}\right)$ and induction period for a single breakdown site [12] as

$$
V_{\mathrm{c}}=\frac{4.606 R T}{\chi F \alpha} \log \left(\frac{J_{\mathrm{m}}}{J^{0} u^{-x / 2}}\right)-\frac{2.303 R T}{\alpha F} \log \left(a_{\mathrm{x}}-\right)
$$

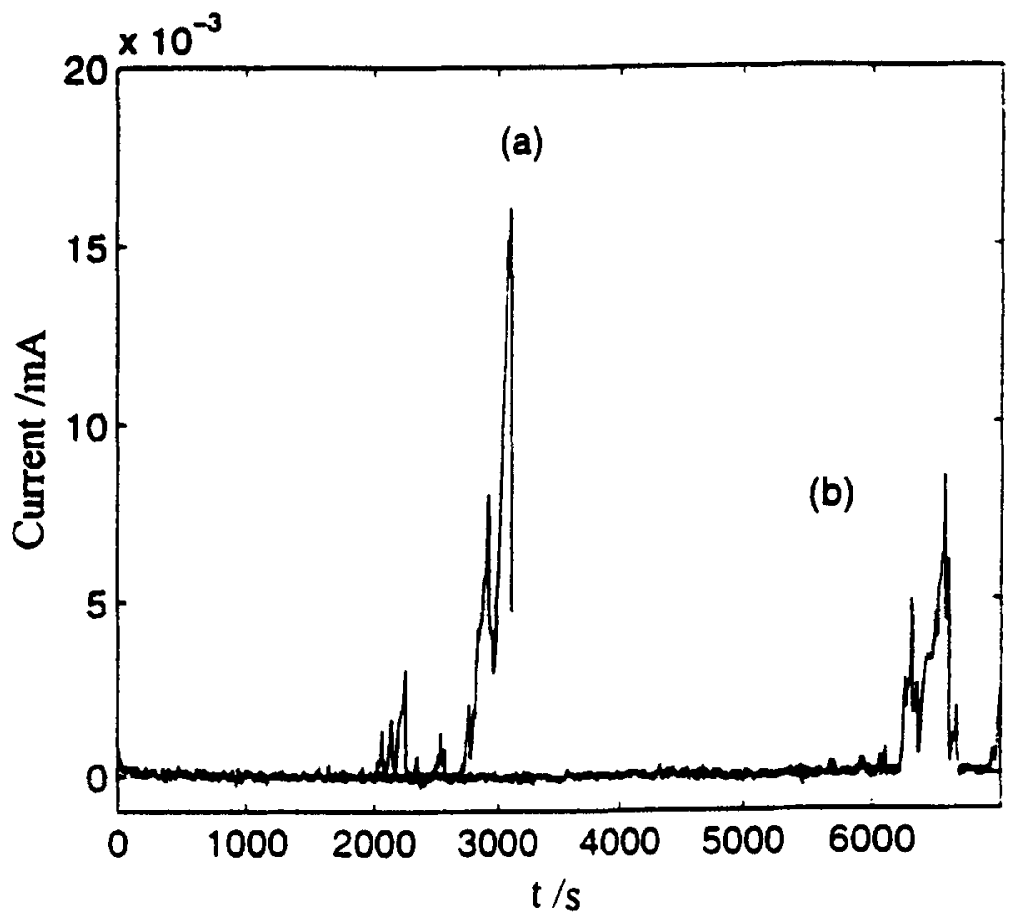

Fig. 8. Current-time decay profiles for type 316 stainless steel polarized at $285 \mathrm{mV}$ (sce) in a neutral $2.5 \times 10^{-2} \mathrm{~mol} \mathrm{dm}^{-3}$ $\mathrm{NaCl}$ solution under conditions of (a) non-illumination, (b) illumination at $300 \mathrm{~nm}$. 
and

$$
t_{\text {ind }}=\xi^{\prime}\left(\exp \left(\frac{\chi \alpha F \Delta V}{2 R T}\right)-1\right)^{-1}+\tau
$$

respectively, where $a_{\mathrm{x}}$ - is the activity of the aggressive anion in the solution, $t_{\text {ind }}$ is the induction period, $\Delta V=V_{\text {app }}-V_{\mathrm{c}}, V_{\text {app }}$ is the applied potential, and $\xi^{\prime}$ is related to the critical concentration of cation vacancies at the metal-film interface. The other parameters are as defined in previous publications [12].

It is proposed that on illumination, incident photons with energies in excess of the bandgap energy generate electron-hole pairs that are separated by the steep potential gradient in a manner that quenches the field, $\epsilon$. Since the parameter $J^{n}$, the flux of cation vacancies across the barrier layer, is directly proportional to $\epsilon$, it can be seen from equation (1) that a decrease in $\epsilon$ leads to an increase in $V_{c}$, the critical breakdown potential. Also $\xi^{\prime}$ is inversely proportional to $\epsilon$, so that a decrease in $\varepsilon$ leads to an increase in $t_{\text {ind }}$, equation (2). Thus, the finding that incident light inhibits the nucleation of pits (Figs 1-8) is consistent with a quenching of $\epsilon$.

It is evident from the variations in the displacement of the breakdown potential and induction time with the wavelength of the incident light (Figs 6 and 7), that only photons with energies in excess of the bandgap energy are successful in enhancing the pitting resistance. Bandgap energies in the region $2.0-3.2 \mathrm{eV}$ reported for $\mathrm{Fe}-\mathrm{Cr}$ alloys, and the onset of sizable photo-currents between 375 and $275 \mathrm{~nm}$ [13-16], agree reasonably well with the data presented here, where the photo-inhibition effect is seen to diminish for wavelengths longer than $375 \mathrm{~nm}$. The lack of a well-defined wavelength at which the photo-inhibition becomes evident is probably associated with sub-bandgap absorption. Although the passive films on stainless steels have been reported as being $n$-type semiconducting oxides, the barrier layer is postulated to be highly defective and amorphous, with a high density of localized states located close to the conduction band edge $[12,13,17-20]$. However, this behaviour is consistent with the generation of electron-hole pairs and the quenching of the electric field strength being responsible for the enhanced resistance to pitting attack.

The data presented in Fig. 5 illustrate further the importance of generating electron-hole pairs and the subsequent quenching of the electric field. It appears that the formation of a precipitate layer on SS304 and SS316 specimens polarized in the alkaline solutions screens the barrier layer from the incident photons, and thus inhibits the generation of electron-hole pairs. This is supported by the experiments in which the photo-inhibition effect was partially restored on addition of the complexing agent, EDTA, to the alkaline test solutions; the complexing agent hinder- ing the formation of the precipitate layer. The nature of this precipitate layer is unclear. However, it may be similar to the iron hydroxide, $\mathrm{Fe}_{x}(\mathrm{OH})_{y}$, formed on iron during periodic passivation and reduction in $\mathrm{NaOH}$, which was removed completely by EDTA [21]. Also, the fact that the photo-inhibition effect remains unaffected (in neutral and acidic solutions), or increases (in alkaline solutions), in the presence of EDTA suggests that it is unlikely that photo-induced reactions, involving oxidized iron, at the filmsolution interface are responsible for the observed photo-inhibition effect.

However, this present work and that of Schmuki and Böhni $[8,9]$ show that the photo-effect persists after the incident radiation has been removed, so that the explanation of the effect cannot reside in the perturbation of the electronic structure alone. It is postulated that suppression of the electric field strength also modifies the vacancy distributions and, indeed, expressions for the concentrations of metal and oxygen vacancies as a function of the field strength have been derived from the PDM and are consistent with this hypothesis [22]. Noting that the cation vacancy diffusivity is of the order of $10^{-19} \mathrm{~cm}^{2}$ $\mathrm{s}^{-1}$ (at least for the passive film on $\mathrm{Ni}$ [12]), and assuming that the thickness of the barrier layer $(L)$ is $3 \mathrm{~nm}$, the relaxation time $(t)$ of the vacancy structure $\left(t \approx L^{2} / D\right)$ is estimated to be of the order of $9 \times 10^{5} \mathrm{~s}$. This is in very good agreement with the period of $220 \mathrm{~h}\left(7.92 \times 10^{5} \mathrm{~s}\right)$ calculated from the data presented in Fig. 4, indicating that the photo-inhibition effect persists until the vacancy structure relaxes back to the state prior to illumination. Also, the data presented in Fig. 2, in which the photoinhibition effect is seen to increase with the illumination period, seem to support this analysis; with extended illumination periods leading to a greater modification of the vacancy structure, which is slow to relax.

It might be postulated that the effects described here could be accounted for by the photo-dissolution of $\mathrm{MnS}$ inclusions. However, this is an electrochemical process and illumination might reasonably bc expected to enhance the noise, contrary to the observations here. In addition, if the dissolution of the sulfide inclusions was enhanced by light, and if this process was ultimately responsible for stable pitting, then one might expect a negative shift in the breakdown potential upon illumination. Indeed, we have observed a decrease in the breakdown potential of SS304 on illuminating with very high intensity $u v$ radiation $\left(1186 \mathrm{~mW} \mathrm{~cm}^{-2}\right)$ [22], which suggests that photo-dissolution of the inclusions occurs only with high intensity illumination. Nevertheless, a role for MnS inclusions in the passivity breakdown on stainless steels has been established [23-26], and this is consistent with the present analysis. According to the PDM, the most susceptible sites on a metal surface to passivity breakdown are those with the highest diffusivities for cation vacancies within the 
barrier (passive) layer. These sites are likely to include the points of intersection between the barrier layer and the inclusion, as previously proposed [12]. In this scenario, passivity breakdown initiates at the periphery of the inclusion and, if conditions are subsequently established that cause the inclusion itself to dissolve substantially, then stable pitting ensues. Indeed, this scenario is consistent with the micrographs published by Ke and Alkire [23], which show that pits initiate at the edges of $\mathrm{MnS}$ inclusions followed by dissolution of the inclusion to form various sulfur products.

Nevertheless, it is also possible that illumination of the stainless steel surfaces lead to an enrichment of chromium in the passive film. Indeed, it is possible that both a chromium enrichment and a quenching of the electric field strength occur in a synergistic manner. However, the significant photo-inhibition effect observed with pure iron $[8,9]$ and pure nickel [6] cannot be explained in terms of such a chromium-enrichment process.

\section{CONCLUSIONS}

The results of this work show that photo-inhibition of pitting corrosion can be achieved for stainless steels on illumination with $u v$ photons. An increase in both the breakdown potential and induction period and a decrease in the frequency of meta-stable pitting events were observed on illumination.

If was found that photo-inhibition of pitting attack depended on the energy of the photons (with photons having energies in excess of the bandgap being more effective) and the $\mathrm{pH}$ of the test solution. It appeared that the precipitate layer formed on passivation of the stainless steels in alkaline solutions $(\mathrm{pH}>10)$ hindered the interaction of the photons with the barrier layer. The addition of a complexing agent, EDTA, to the test solution, which restored partially the photo-inhibition effect, supported this hypothesis. It was found, also, that the photo-effect persisted after the incident radiation was removed, surviving for periods of up to $220 \mathrm{~h}$.

These findings may be explained within the framework of the Point Defect Model (PDM) in terms of the generation of electron-hole pairs and the resulting quenching of the electric field strength. This in turn is predicted to modify the vacancy structure, leading to an enhancement in the pitting resistance of the steels that persists for some $220 \mathrm{~h}$.

\section{ACKNOWLEDGEMENTS}

The authors gratefully acknowledge the support of this work by the Electric Power Research Institute,
Palo Alto, California, under Contract Number RP8041-07, and by the U.S. Department of Eneryy/Basic Energy Sciences, under Grant Number DE-F602-91ER45461.

\section{REFERENCES}

1. R. G. Wendt, W. C. Moshier, B. Shaw, P. Miller and D. L. Olson, Corrosion 50, 819 (1994).

2. B. A. Shaw, G. D. Shaw, T. L. Fritz, B. J. Rees and W. C. Moshier, J. Electrochem. Soc. 138, 3288 (1991).

3. A. J. Sedriks, Corrosion of Stainless Steels, The Electrochemical Society, Princeton, NJ (1979).

4. P. M. Natishan, E. McCafferty and G. K. Kubler, J. Electrochem. Soc. 135, 321 (1988).

5. M. Ohi, H. Nishihara and K. Aramaki, Corrosion 50, 226 (1994).

6. S. J. Lenhart, M. Urquidi-Macdonald and D. D. Macdonald, Electrochim. Acta 32, 1739 (1987).

7. E. Sikora, M. W. Balmas, D. D. Macdonald and R. C. Alkire, Corros. Sci. 38, 97 (1996).

8. P. Schmuki and H. Böhni, Proceedings of the Seventh International Symposium on Passivity of Metals and Semiconductors, Clausthal-Zellerfeld, Germany, August 21-26 (1994).

9. P. Schmuki and H. Böhni, Electrochim. Acta 40, 775 (1995).

10. J. M. Bastidas and J. D. Scantlebury, Corros. Sci. 25 , 377 (1985).

11. J. M. Bastidas and J. D. Scantlebury, Corros. Sci. 26, 341 (1986).

12. D. D. Macdonald, J. Electrochem. Soc. 139, 3434 (1992).

13. A. Di Paola, D. Shukla and U. Stimming, Electrochim. Acta 36, 345 (1991).

14. A. M. Simoes, M. G. S. Ferreira, B. Rondot and M. da Cunha Belo, J. Electrochem. Soc. 137, 82 (1990).

15. P. Schmuki and H. Böhni, J. Electrochem. Soc. 139, 1908 (1992)

16. H. Ezaki, G. P. Berera and R. M. Latanision, The Electrochemical Society Proceedings, 94-26, p. 127 (1995).

17. U. Stimming and J. W. Schultze, Ber. Bunsenges Phys. Chem. 80, 1297 (1976).

18. M. H. Dean and U. Stimming, Corros. Sci. 29, 199 (1989).

19. M. J. Kloppers, F. Bellucci and R. M. Latanision, Corrosion 48, 229 (1992).

20. K. Azumi, T. Ohtsuka and N. Sato, J. Electrochem. Soc. 134, 1352 (1987).

21. Z. Szklarska-Smialowska, T. Zakroczymski and C. J. Fan, J. Electrochem. Soc. 132, 2543 (1985).

22. D. D. Macdonald and D. Heaney, to be published.

23. R. Ke and R. Alkire, J. Electrochem. Soc. 139, 1573 (1992).

24. J. Stewart and D. E. Williams, Corros. Sci. 33, 457 (1992).

25. R. M. Rynders, C. H. Paik, R. Ke and R. C. Alkire, J. Electrochem. Soc. 141, 1439 (1994).

26. G. T. Burstein and P. C. Pistorius, Corrosion 51, 380 (1995). 